\title{
Hydrogen Storage of a Fixed Bed of Nanocrystalline Mixed Oxides
}

\author{
M. Abdus Salam, Suriati Sufian, Ye Lwin, and T. Murugesan \\ Chemical Engineering Department, Universiti Teknologi PETRONAS, Bandar Seri Iskandar, Tronoh, Perak 31750, Malaysia
}

Correspondence should be addressed to M. Abdus Salam; salam.bcsir@gmail.com

Received 12 December 2012; Accepted 1 January 2013

Academic Editors: M. Mirzaei and J. Zeng

Copyright (C) 2013 M. Abdus Salam et al. This is an open access article distributed under the Creative Commons Attribution License, which permits unrestricted use, distribution, and reproduction in any medium, provided the original work is properly cited.

Nanocrystalline hydrotalcite derived mixed oxides containing magnesium, cobalt, and aluminum (MCAM) $\left(\mathrm{M}_{(1-x)} \mathrm{Al}_{x} \mathrm{O}_{(1+x / 2)}\right.$; $\mathrm{M}=\mathrm{Mg}$ or $\mathrm{Co} / \mathrm{Mg}$ and $\mathrm{Co}$ and $x=$ molar ratios) have been synthesized successfully and showed reversible hydrogen storage capacity at near ambient condition using fixed bed. ICP-MS and XRD analysis confirmed the adsorbent phases and their homogeneity. Adsorbent morphology and textural properties have been characterized using FESEM, BET and TEM analysis techniques. Nanocrystalline and porous mixed oxides exhibited $3 \mathrm{wt} \% \mathrm{H}_{2}$ storage capacity and desorbed $57 \%$ of adsorbed $\mathrm{H}_{2}$. Spillover phenomena are observed through FTIR analysis. Adsorption enthalpy $(\Delta H)$ and entropy $(\Delta S)$ change were $-25.58 \mathrm{~kJ} / \mathrm{mol}$ and $-59.98 \mathrm{~J} / \mathrm{mol} \cdot \mathrm{K}$, respectively, which implied a prospective feature of reversible hydrogen adsorption on nano-crystalline mixed oxide.

\section{Introduction}

Nanocrystalline particles are believed to enhance hydrogen storage and release kinetics without any catalyst $[1,2]$. Nanoparticles often show different behavior compared to bulk particles and are applied, for instance, in catalysis $[3,4]$. The structure and properties of hydrogen storage nanomaterials have been studied extensively over the last 10 years that can be summarized from few reviews [5-8]. Hydrogen is a potential source to store and transport as energy carrier. The outcome of the process has zero emission except water thus, it is considered environment friendly. Several ways of $\mathrm{H}_{2}$ storage have been investigated such as high pressure gas, liquid hydrogen, and adsorption on porous materials, complex hydrides, and hydrogen intercalation in metals. None of these technologies satisfy all the criteria for effective hydrogen storage. It is believed that adsorption at near-ambient conditions on porous media with weak Van der Waals interaction can fulfill the criteria that have been set by the U.S. Department of Energy (DOE) $[9,10]$.

Nanocrystalline mixed oxides have gained considerable attention in being designed as adsorbent due to their wide variety of chemical compositions [11, 12] and their textural and surface morphology that can be tuned. A Nanocrystalline sorbent might be a potential hydrogen storage material due to its physisorption capacity of $\mathrm{H}_{2}$ in a molecular form [13]. Mixed oxides with a higher surface area and favorable pore volume can adsorb hydrogen efficiently in different ways $[14,15]$. Mixed oxides have been reported as a good adsorbent for carbon dioxide $\left(\mathrm{CO}_{2}\right)$ [16], nitrogen oxide $(\mathrm{NO})$, and sulfur oxide $[17,18]$ gas. In the gas phase, hydrogen readily attaches to other molecules or atoms. The molecular cations $\mathrm{H}_{2}{ }^{+}$and $\mathrm{H}_{3}{ }^{+}$have only a transitory existence in the gas phase. The weakest force (Van der Waals) occurs due to its random motion of electrons. Metal oxides are surrounded by $\mathrm{H}_{2}$ resulting in an instantaneous polarity on the atom. During this time, the polarized atom acts as a weak dipole. The molecular form of $\mathrm{H}_{2}$ binds with the oxide surface under ambient conditions induced by Van der Waals forces ( $\mathrm{meV}$ range).

Fixed bed adsorption columns offer many advantages for finding potential $\mathrm{H}_{2}$ adsorbents due to the high surface to volume ratio; efficient heat and mass transfer improve gas mixing and control the process parameters effectively. They have diversified applications such as in the petroleum industry, as in dehydration and purification of natural gases [19-21]. However, experimental condition, such as temperature and pressure and microbalance make regeneration more complicated and costly. A fixed bed with a hydrogen analyzer has been used to investigate the hydrogen adsorption on mixed oxides that makes the bed more precise and effective. 


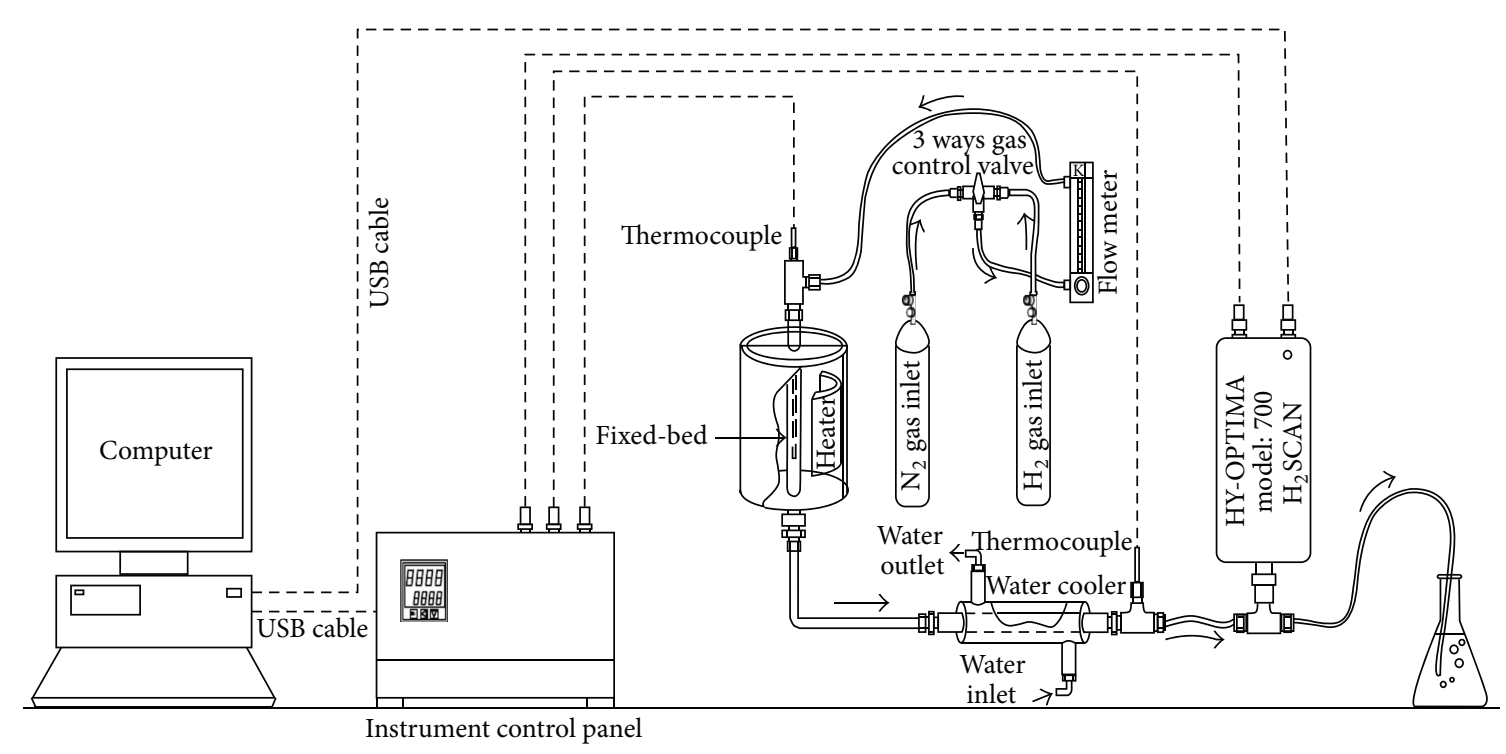

FIgURE 1: Diagram of the full fixed bed setup.

The objectives of this study using the fixed bed are to explore the hydrogen adsorption capacity and its thermodynamics and kinetics of nanocrystalline mixed oxides at near ambient conditions.

\section{Experimentation and Methods}

2.1. Preparation of Mixed Oxides as Adsorbents. The mixed oxides containing magnesium, cobalt, and aluminum were synthesized by using modified coprecipitation method from metal nitrate precursors and $\mathrm{Na}_{2} \mathrm{CO}_{3}$ as the precipitating agent. Three solutions, each containing appropriate quantities of the metal nitrate precursors of magnesium $(0.75 \mathrm{M})$, cobalt $(0.75 \mathrm{M})$, and aluminum $(0.25 \mathrm{M})$, were prepared. Mixed nitrate solution was added dropwise into a $0.5 \mathrm{M}$ sodium carbonate solution maintained at $55^{\circ} \mathrm{C}$ with a vigorous stirring. At temperature $55^{\circ} \mathrm{C}$, anion exchange occurs moderately and formation of hydrotalcite is homogenous due to better neutralization [22]. Nitrogen gas was purged to the reaction vessel during whole synthesis process to remove carbonate from the solution. The $\mathrm{pH}$ was varied initially from 12.5 to 9. The resulting precipitates were washed several times to remove the excess $\mathrm{Na}^{+}$and $\mathrm{NO}_{3}{ }^{-}$ions, then filtered, and dried. The fresh dried material was calcined at $800^{\circ} \mathrm{C}$ for two hours to convert the mixed oxides. The mixed oxides samples were designated by MCAM-xyz, respectively; MCAM stands for Mg-Co-Al mixed oxides, and xyz stands for the molar ratios of the $\mathrm{Mg}$ : $\mathrm{Co}: \mathrm{Al}$ samples.

\subsection{Experiment (Fixed Bed) Setup Details and Theory.} The full experimental setup consisting of a stainless steel (SS316L) tube column (internal diameter $=11 \mathrm{~mm}$ and height $=169 \mathrm{~mm}$ ) is shown in Figure 1 . A furnace with an $800 \mathrm{~W} / 240$ VAC ceramic heater was used for heating the sample inside the bed, and a PID-type controller maintained the temperature of the adsorbent inside. A flow controller was used to control the inlet gas flow to the bed. Outlet gases from the fixed-bed passed through the water condenser to maintain the outlet gas temperature. A hydrogen gas analyzer (HY-OPTIMA-700, customized process parameters of analyzer: flow rate $(20-80 \mathrm{~mL} / \mathrm{min})$, gas temp. $\left(20-80^{\circ} \mathrm{C}\right)$, and pressure (1-2 atm.)) was used to detect the concentration of hydrogen gas.

A field calibration of analyzer has been carried out by following customized specification of analyzer and using ambient conditions to get the precise concentration values. The system was calibrated without sample into the bed and using inert material with similar particle size $(18-25 \mathrm{~nm})$ of mixed oxides. The used premixed gas (premixed by Linde Malaysia sdn Bhd (100783-w)) as inlet and desorbed gas composition has been analyzed and ensured with a quadrupole mass spectrometer (M-201QA-TDM, canon, anelva). The concentration of the $\mathrm{H}_{2}$ gas is almost the same as premixed gas.

After the calibration of the system, purified nitrogen gas was purged to bed to turn the analyzer to active mode (green LED appeared). The sample (1 gm adsorbent) was placed on the sample holder/bed and heated to $150^{\circ} \mathrm{C}$ with a temperature ramp of $10^{\circ} \mathrm{C} / \mathrm{min}$ under a pure nitrogen gas atmosphere and continued with the same conditions for 2 hours to activate the adsorbent. Cool down the adsorbent to room temperature (or the desired temp.), and different or required concentrated hydrogen gas $(5 \%$, volume percent and balance with $\mathrm{N}_{2}$ gas and gas flow $=50 \mathrm{~mL} / \mathrm{min}$ ) with a pressure (2 bar) was exposed to fixed bed in order to conduct $\mathrm{H}_{2}$ adsorption on the adsorbent (1 gm). After $\mathrm{H}_{2}$ gas adsorption, the same bed was used to desorb the $\mathrm{H}_{2}$ gas under $\mathrm{N}_{2}$ gas flow $(50 \mathrm{~mL} / \mathrm{min})$ with a temperature ramping $10^{\circ} \mathrm{C} / \mathrm{min}$ from $30^{\circ} \mathrm{C}$ to $150^{\circ} \mathrm{C}$. Data acquisition was carried out in two ways: (1) using a USB6008 DAQ card and LABVIEW software: (2) the gas concentration was measured via the RS232 converter using a hyperterminal of the Windows XP programme. 


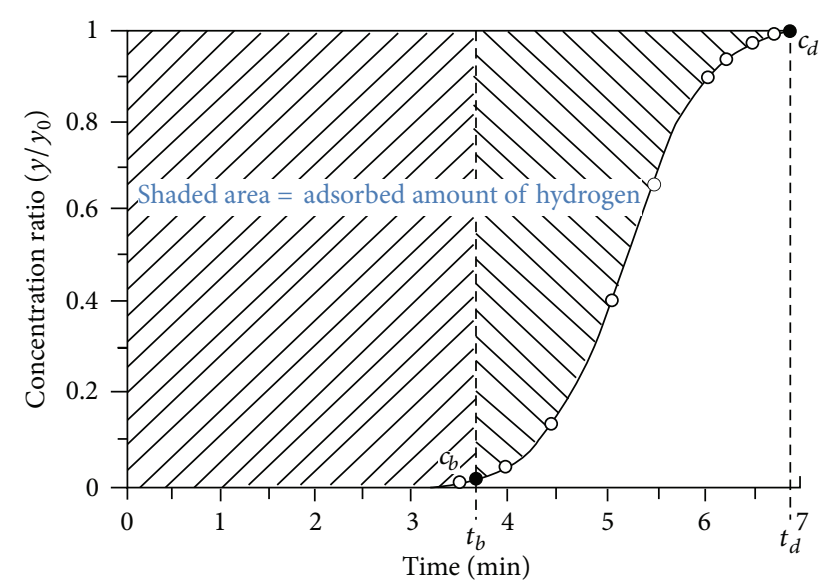

Figure 2: A typical breakthrough curve of gas adsorption onto adsorbent.

The breakthrough curves obtained from the experiments were used to fit a sigmoidal-type mathematical expression so that the ratio $y / y_{0}$ can be expressed as function of time. The fitting correlation coefficient $\left(R^{2}\right)$ corresponds to the variance of the collected data:

$$
\frac{y}{y_{0}}=\frac{t}{\left(t+A \cdot e^{-B \cdot t}\right)}
$$

$A$ and $B$ are the fitting parameters, $y$ and $y_{0}$ are the final and initial concentrations of hydrogen, respectively, and $t$ is the adsorption time. The hydrogen adsorption in the bed can be determined by a dynamic mass balance, which requires a numerical integration of the data. Using the breakthrough ((Figure 2) typical breakthrough curve) curve the capacity of the fixed bed for $\mathrm{H}_{2}$ adsorption or mass adsorbed by the bed $\left(M_{\mathrm{ads}}\right)$ can be calculated using the following equation [23]:

$$
M_{\mathrm{ads}}=\frac{Q_{T}(M W)}{\left(R T / P_{A}\right)}\left[\Delta t-\int_{0}^{t}\left(\frac{y}{y_{0}}\right) d t\right],
$$

where $t$ is the time, equivalent to the total or stoichiometric capacity, $M_{\mathrm{ads}}=$ adsorbed mass, $Q_{T}=$ flow of gas, $y_{0}=$ inlet gas concentration (used gas concentration 5\%, 10\% and $15 \%$ hydrogen and balance with nitrogen gas), and $P_{A}=$ partial pressure of inlet $\mathrm{H}_{2}$ gas. All parameter units have been converted to SI unit for calculation and adsorption capacity of the bed determined by using the following equation:

$$
W=\frac{M_{\mathrm{ads}}}{M_{\mathrm{bed}}},
$$

where $M_{\text {bed }}=$ mass of the bed. The mass of the desorbed $\mathrm{H}_{2}$ can be calculated by the numerical integration of the concentration profiles:

$$
M_{\text {des }}=\frac{P \cdot Q_{N_{2}} \cdot(M W)}{R T} \int_{0}^{t} \frac{y_{\text {out }}}{1-y_{\text {out }}} .
$$

The adsorbed amount of $\mathrm{H}_{2}$ for different concentrated inlet gas was calculated by using equation (2) in the saturation
TABLE 1: Textural properties and elemental composition of MCAM with different molar ratios.

\begin{tabular}{lccccc}
\hline \multirow{2}{*}{ Adsorbent } & \multicolumn{2}{c}{ ICP-MS results/(wt\%) } & \multicolumn{2}{l}{ BET surface } & Pore \\
& $\mathrm{Mg}$ & $\mathrm{Co}$ & $\mathrm{Al}$ & $\mathrm{area} /\left(\mathrm{m}^{2} \mathrm{~g}^{-1}\right)$ & size/(nm) \\
\hline MCAM 031 & - & 12.33 & 4.17 & 165 & 14 \\
MCAM 121 & 3.90 & 7.91 & 3.98 & 321 & 11 \\
MCAM 211 & 8.21 & 4.34 & 4.11 & 288 & 12 \\
MCAM 301 & 12 & - & 5.81 & 124 & 16 \\
\hline
\end{tabular}

condition $\left(y / y_{0}=1\right)$ and was used to sketch the adsorption isotherms. The experimental adsorption isotherms were compared to the models of the isotherms proposed by the Langmuir, Freundlich, respectively. The parameters in these equations (model equations) were fitted using DataFit 9.0 to calculate the maximum adsorbed $\mathrm{H}_{2}$ amount.

2.3. Adsorbent Characterization Technique. An elemental chemical analysis for magnesium, cobalt, and aluminum has been performed using the inductively coupled plasma mass spectrometry (ICP-MS), from Agilent 7500 series. Mixed oxides identification and its crystallinity were analyzed by powder X-ray diffraction (XRD) technique using a Bruker D8 advanced diffractometer with $\mathrm{Cu}-\mathrm{K}_{\alpha}$ radiation. Surface morphology of the mixed oxides was studied by using a field-emission scanning electron microscope (FESEM) from CARL Zeiss Supra 55VP instrument equipped with the Oxford INCA 400 EDX microanalysis system. The characterization of microstructure of mixed oxides has been carried out using a CARL Zeiss LIBRA ${ }^{R}$ 200FE transmission electron microscope with an acceleration voltage of $200 \mathrm{kV}$ on ultrasonically dispersed samples in isopropanol. Nitrogen gas adsorption-desorption isotherms of the samples were obtained using a Micromeritics ASAP 2020 Sorptometer. The total surface areas $\left(S_{\mathrm{BET}}\right)$ were calculated using the Brunauer Emmet-Teller (BET) method. Fourier transform infrared (IR) spectra of adsorbed hydrogen species were performed with JUSCO FT/IR 4200 spectrometer at a resolution of $4 \mathrm{~cm}^{-1}$ under a static condition. Prior to each experiment a selfsupporting sample disk $\left(14 \mathrm{mg} \cdot \mathrm{cm}^{2}\right)$ was placed in IR cell. The sample was pretreated with $5 \% \mathrm{H}_{2}$ (V/V\% and balance with $\mathrm{N}_{2}$ ) at 1 bar for 2.5 hours.

\section{Results and Discussion}

3.1. Adsorbent Properties. The elemental chemical analysis using ICP-MS is summarized in Table 1 where the results are shown in metal weight percent. The molar ratios $\left(\mathrm{M}^{\mathrm{II}} / \mathrm{M}^{\mathrm{III}}\right.$ and $\mathrm{Mg} / \mathrm{Co}$ ) of the metal in the mixed oxides are close to the value in the starting solutions (synthesis molar ratio). The results demonstrate that the degrees of the precipitation of the metals are about $95 \%$, and the mixed oxides are homogenous.

The XRD patterns of the mixed oxides shown in Figure 3 indicate that the precursor of the mixed oxides has been decomposed fully at $800^{\circ} \mathrm{C}$ and has led to the various oxide derivatives. For samples containing both $\mathrm{Mg}$ and $\mathrm{Co}$, the oxides are mainly of the spinel phase with the characteristic 


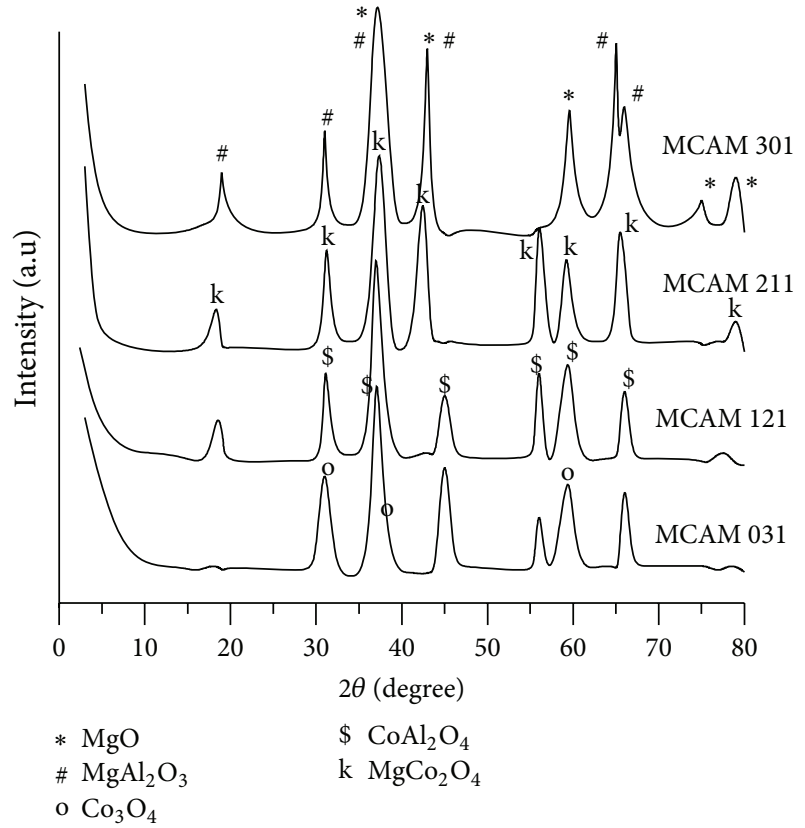

Figure 3: The XRD pattern of MCAM with different molar raios.

diffraction peaks of $\mathrm{Co}_{2} \mathrm{AlO}_{4}$ (JCPDS 38-0814), $\mathrm{MgCo}_{2} \mathrm{O}_{4}$ (JCPDS 02-1073(N)), and magnesium aluminates, $\mathrm{MgAl}_{2} \mathrm{O}_{4}$ (JCPDS-01-1157(D)), in addition to the individual spinels: cobalt oxides, $\mathrm{Co}_{3} \mathrm{O}_{4}$ (JCPDS 42-1467), and magnesium oxides MgO (JCPDS-01-1235(D)). In these phases, Co exists as divalent or higher-valent and they have very similar XRD patterns. The situation of overlapping is observed between $\mathrm{MgO}$ and some of the spinels. From our investigation, $\mathrm{Mg}$ rich mixed oxides show a larger crystallite size than Co-rich samples which is because of well formation of magnesium oxides crystal at $\mathrm{pH}=9$ or less than that. The elemental analysis and XRD results clearly correspond that the mixed oxides are homogenous and nanocrystalline. The measured crystal size is $18-25 \mathrm{~nm}$.

The FESEM image of MCAM 121 exhibits a porous microstructure which can be ensured by BET nitrogen adsorption-desorption at $-196^{\circ} \mathrm{C}$. The surface morphology of the mixed oxides depends on the synthesis condition (temperature, $\mathrm{pH}$ ) and chemical composition. The mixed oxides show two types of morphology which are the hexagonal platelike (not shown) with an opening pore and the coral-like (Figure 4) with a pore size of 10-14 $\mathrm{nm}$ and slit-shape pore between two plates. Porous materials with plate-like particles have geometry with opening between plates. Higher contents of cobalt, which has a larger ionic radius and distorts the oxide structure, result in the coral-like morphology.

The microstructure of $\mathrm{Mg}$-Co-Al mixed oxides is investigated by transmission electron microscopy (TEM) together with their electron diffraction pattern. The average crystal size was $15-25 \mathrm{~nm}$. It can be observed that selected area diffraction pattern (SAED) of mixed oxides before (Figure 5(a)) and after hydrogen adsorption (Figure 5(b)) consisted of few rings and dispersed bright spot. The micrograph correspond that the adsorbent are nano-sized polycrystalline. From observation, it has been realized that amorphous mixed oxides (like MCAM 031, not shown) were unstable when exposed to electron beam for long time and appear in weak crystalline form. It has been observed that nanocrystalline powder shows higher hydrogen adsorption capacity than amorphous powder samples which agree with the work of Tanaka et al. [24]. As a result, nanocrystalline material shows well-established diffusion path for hydrogen atom along the numerous grain boundaries and slit shaped pore with opening geometry. The nominal differences of SAED pattern have been observed between mixed oxides and hydrogen adsorbed mixed oxides due to the physisorption and minor chemisorption that can be observed by Table 2 .

The nitrogen adsorption-desorption isotherms of the Mg-Co-Al mixed oxides with different molar ratios showed a type IV isotherm (not shown) which indicates that the investigated materials are mesoporous. The slit-like pore allowed the adsorption of the $\mathrm{H}_{2}$ molecule with nearest neighbor interactions. Mixed oxides with different molar ratios exhibited quite a narrow pore size distribution (PSD). The narrow pore size distribution curve (not shown here) implied that this material possessed very regular pore channels. The textural properties obtained from the BET analysis are summarized in Table 1.

\section{2. $\mathrm{H}_{2}$ Breakthrough Curve and Its Adsorption Characteris-} tics. The linear driving force (LDF) approximation for the mass transfer has been used to describe the adsorption breakthrough curves obtained from the experiments. Variance model (1) is fitted with the breakthrough curves, and all fitting correlation coefficient $\left(R^{2}\right)$ indicated that the experimental data for the breakthrough curves are well fitted and one fitting curve is shown (MCAM 031 data) in Figure 6 as an inset. The adsorbed mass of $\mathrm{H}_{2}$ in the saturation condition $\left(y / y_{0}=1\right)$ is determined for each experiment by using (2), a condition in which the bed and feeding of the gaseous mixture reached an equilibrium. Different $\mathrm{H}_{2}$ gas concentrations $(5,10$, and $15 \%(\mathrm{v} / \mathrm{v}))$, as the inlet gas of the fixed bed, have been purged, resulting in different breakthrough curves but the adsorption capacity is almost the same. The breakthrough curves of the hydrogen adsorption on the mixed oxides with different molar ratios at a $30^{\circ} \mathrm{C}$ temperature are steep and indicate that the porous adsorbent is medium dispersive and the breakthrough curves are symmetrical [25]. In a mixed oxides $\mathrm{M}-\mathrm{O}-\mathrm{M}^{\prime}$ system (for example, $\mathrm{Co}_{2} \mathrm{AlO}_{4}=$ $\mathrm{Co}^{3+}\left(\mathrm{Al}^{3+} \mathrm{Co}^{3+}\right) \mathrm{O}_{4}^{-}$or $\left.\mathrm{Al}^{3+}\left(\mathrm{Al}^{3+} \mathrm{Co}^{3+}\right) \mathrm{O}_{4}^{-}\right)$, the binding energy of the metals is generally altered [26]. Any of them $\left(\mathrm{Al}^{3+}\right.$ or $\left.\mathrm{Co}^{3+} / \mathrm{Co}^{2+}\right)$ might be more ionic and produce an electric field. So, the polarized hydrogen molecules by those ions can then bind to it in a quasi-molecular form [27] which is intermediate between physisorption and chemisorption and can be desorbed at a temperature of $150^{\circ} \mathrm{C}$. To adsorb $\mathrm{H}_{2}$ in this form less activation energy is involved which is equal to Van der Waals range energy (meV).

The increment of the $\mathrm{H}_{2}$ concentration effect, the breakthrough curves due to higher concentration expedites the mass transfer of hydrogen to the adsorbent surface. Less 


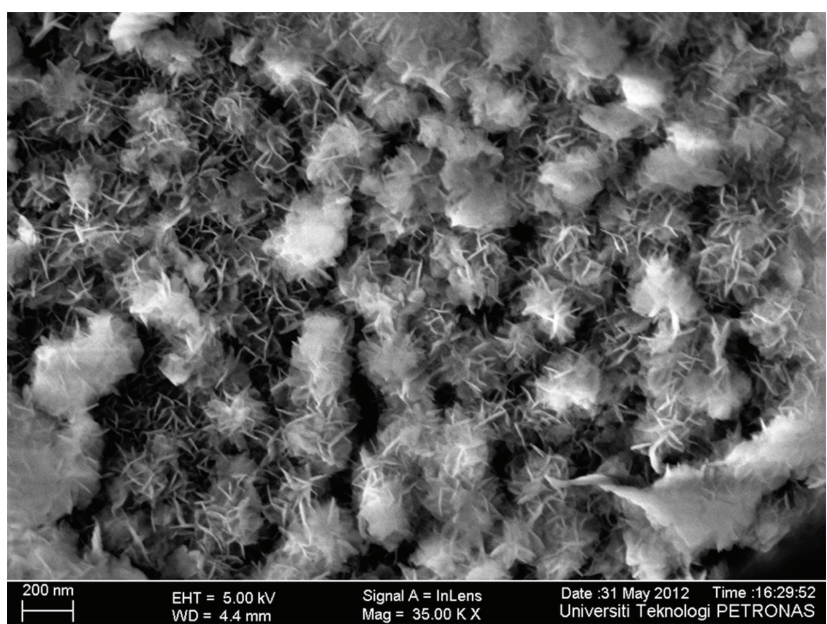

FIgURE 4: The FESEM image of MCAM 121.

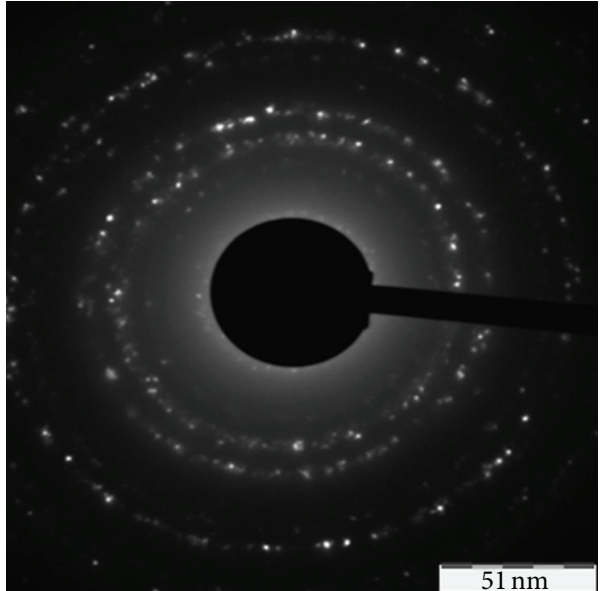

(a) Before $\mathrm{H}_{2}$ Adsorption

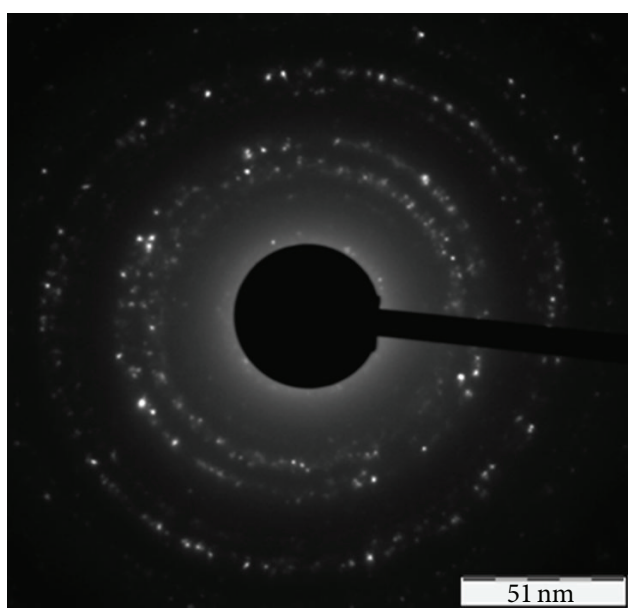

(b) After $\mathrm{H}_{2}$ Adsorption

FIGURE 5: SAED pattern of adsorbent (a) before hydrogen adsorption and (b) after hydrogen adsorption.

concentrated $\mathrm{H}_{2}$ gas as inlet shows less steep breakthrough curves than higher concentrated gas, and saturation period is also longer than the higher concentrated inlet $\mathrm{H}_{2}$ gas. The breakthrough curve of the $\mathrm{H}_{2}$ adsorption (Figure 6) at a lower temperature $\left(30^{\circ} \mathrm{C}\right)$ on the fixed bed of mixed oxide shows a higher capacity than at the higher temperature. The adsorption capacity decreases with an increased temperature (Figure 7) but the adsorption rate is different at $60^{\circ} \mathrm{C}$ and $90^{\circ} \mathrm{C}$ which indicates that the adsorption is physisorption dominant. Unreduced mixed oxides showed good $\mathrm{H}_{2}$ adsorption; however, this might be due to its physisorption and intermediate adsorption. A repeated cycle of the $\mathrm{H}_{2}$ adsorption on mixed oxides is carried out by being reactivated the adsorbent under flow of $\mathrm{N}_{2}$ at $30-1500^{\circ} \mathrm{C}$. The results showed that the $\mathrm{H}_{2}$ adsorption was reversible and the capacity of the adsorbent is restored after reactivation.

A desorption study has been carried out by ramping the temperature from room temperature to $150^{\circ} \mathrm{C}$ under $50 \mathrm{~mL} / \mathrm{min} \mathrm{N}_{2}$ flow at 1 bar. The desorption curves of MCAM
TABLE 2: Adsorbed and desorbed amount of hydrogen.

\begin{tabular}{lccc}
\hline Adsorbent & $\begin{array}{c}\text { Ads. } \\
\text { Capacity/(mg/g } \\
\text { ads.) }\end{array}$ & $\begin{array}{c}\text { Des. } \\
\text { Capacity/(mg/g } \\
\text { ads.) }\end{array}$ & $\begin{array}{c}\text { Desorption (in } \\
\text { percent) }\end{array}$ \\
\hline MCAM 031 & 19.10 & 8.31 & 43.51 \\
MCAM 121 & 28.72 & 14.31 & 49.82 \\
MCAM 211 & 21.69 & 10.09 & 46.51 \\
MCAM 301 & 9.25 & 5.34 & 57.73 \\
\hline
\end{tabular}

with different molar ratios are shown in Figure 8; the desorbed amount of $\mathrm{H}_{2}$ is calculated using (4), and summarized in Table 2. From the result (Table 2), it can be concluded that MCAM 121 adsorbed the highest amount of $\mathrm{H}_{2}(28.72 \mathrm{mg} / \mathrm{g})$ and desorbed around 50\% of that adsorbed amount. Cobalt oxides showed better interaction and performances because of their surface morphology, consisted with nano scale 


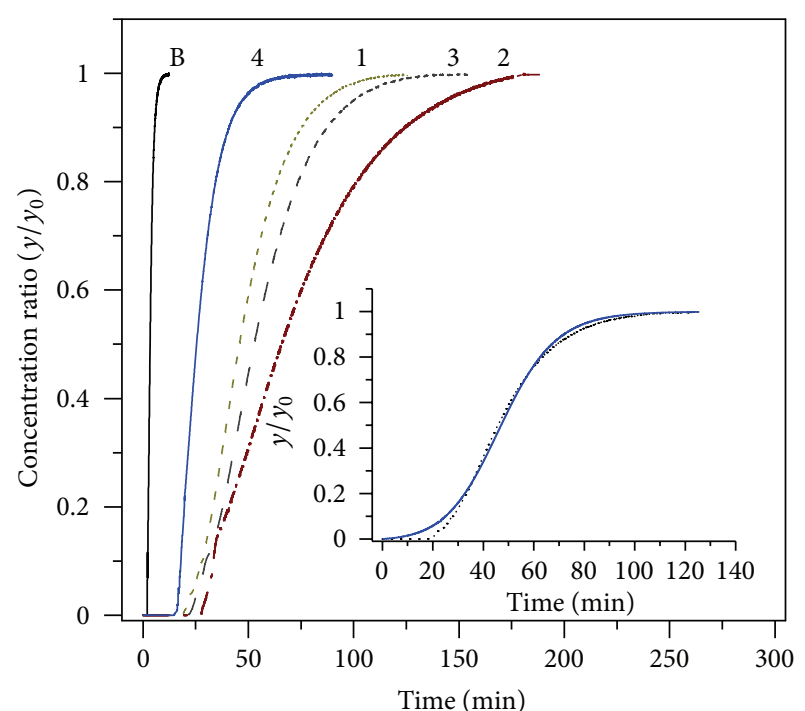

...... Expt. data (MCAM 031)

(B) Blank test

_ Fitting of equation (1)

(1) MCAM 031

(2) MCAM 121

(3) MCAM 211

(4) MCAM 301

FigURE 6: $\mathrm{H}_{2}$ adsorption breakthrough (using concen. 5\% $\mathrm{H}_{2}$ (mol\%) or $4.34 \mathrm{gm} / \mathrm{m}^{3}$ ) curves of MCAM with different molar ratios and data fitting curve with variance model as inset.

particle and mesoporous which was suitable enough for the hydrogen adsorption.

MCAM 121 has been used as a representative adsorbent for further investigations such as comparisons with different isotherms models, kinetics, and thermodynamics. The adsorption isotherms were incurred using the adsorbed $\mathrm{H}_{2}$ by the MCAM 121 that are calculated using breakthrough curves in a saturated condition for different concentrated $\mathrm{H}_{2}$ gas. The experimental data point and Langmuir fitting curve are shown in Figure 9. According to the IUPAC classification, the adsorption isotherm curves are characteristically favorable type (type 1) curves. The isotherms (data points) were fitted with the Langmuir, Fruendlich, respectively, and the fitting parameters of those models are summarized in Table 3. The maximum adsorbed amount of $\mathrm{H}_{2}$ derived from the Langmuir model, and it is $29.97 \mathrm{mg} / \mathrm{g}$ adsorbent (3 wt\%). The trends of the model isotherm indicated that the adsorption is physisorption dominant and the bed capacity decreased at $90^{\circ} \mathrm{C}$ which can be observed by the breakthrough curves (Figure 7).

A typical FTIR spectrum of MCAM 121 shows characteristic IR bands at 564.44, 674.47, 829.72, 1384.46, 1629.96 and $3447.49 \mathrm{~cm}^{-1}$ (shown in Figure 10). The $\mathrm{H}-\mathrm{O}-\mathrm{H}$ bending of water is observed at $1629.96 \mathrm{~cm}^{-1}$. The band at $3447.49 \mathrm{~cm}^{-1}$ is due to the $\mathrm{OH}$ stretching mode of $\mathrm{OH}$ group hydrogen bonded to carbonate anions and free carbonate at $1384.46 \mathrm{~cm}^{-1}$. Cobalt oxides and its spinel showed the vibrational band at 564.44 and $674.47 \mathrm{~cm}^{-1}$ [26]. The vibrational band at $829.72 \mathrm{~cm}^{-1}$ corresponds to the magnesium oxides.

Infrared spectroscopy is an important technique used to study the presence of hydrogen which can be observed with

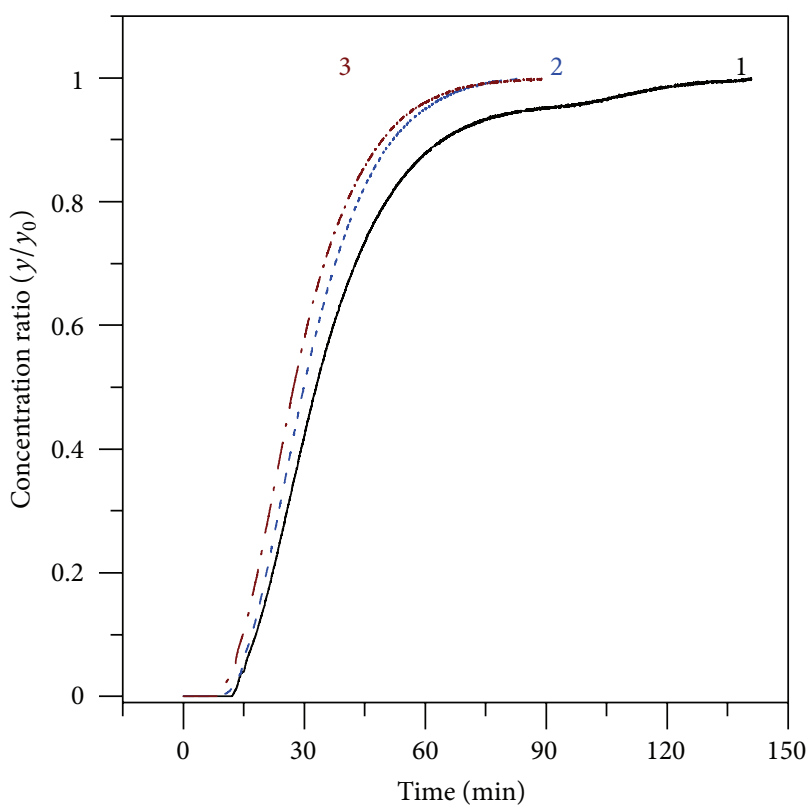

Breakthrough curve at (1) $30^{\circ} \mathrm{C}(2) 60^{\circ} \mathrm{C} \mathrm{(3)} 90^{\circ} \mathrm{C}$

FigURE 7: $\mathrm{H}_{2}$ breakthrough curve (using concen. $10 \% \mathrm{H}_{2}$ (mol\%) or $8.68 \mathrm{gm} / \mathrm{m}^{3}$ ) of MCAM 121 at different temperature.

TABLE 3: Hydrogen uptake calculation using different isotherms.

\begin{tabular}{lccc}
\hline \multicolumn{4}{c}{ Langmuir, $W=W_{m} \cdot K_{L} \cdot C /\left(1+K_{L} \cdot C\right)$} \\
$T_{L}\left({ }^{\circ} \mathrm{C}\right)$ & $W_{m} /(\mathrm{mg} / \mathrm{g})$ & $K_{L}$ & $R^{2}$ \\
\hline 30 & 29.97 & 2.97 & 0.99 \\
60 & 16.95 & 2.10 & 0.99 \\
90 & 13.86 & 1.24 & 0.99 \\
\hline \multicolumn{4}{c}{ Freundlich, $W=K_{F} \cdot C^{1 / n}$} \\
$T_{F}\left({ }^{\circ} \mathrm{C}\right)$ & $K_{F}$ & $n$ & $R^{2}$ \\
\hline 30 & 3.93 & 24.39 & 0.98 \\
60 & 3.15 & 15.88 & 0.99 \\
90 & 2.72 & 9.26 & 0.98 \\
\hline
\end{tabular}

$W_{m}$ Maximum adsorbed amount, $W$ ads. amount; $K$ equilibrium constant, $C$ concentration; $R$ correlation coefficient.

the change of IR transmittance. The effect of the hydrogen presence has already been observed for $\mathrm{Pt} / \mathrm{TiO}_{2}$ [32] and $\mathrm{Ru} / \mathrm{ZnO}$ [33]. Adsorption of $\mathrm{H}_{2}$ on mixed oxides causes the appearance of IR bands at $3840.96 \mathrm{~cm}^{-1}$ due to the hydrogen species dissociatively adsorbed on mixed oxides and spillover to the support oxides $\left(\mathrm{Al}_{2} \mathrm{O}_{3}\right)$ which can promote several catalytic reaction involving $\mathrm{H}_{2}$ as a reactant [34]. A small loss of transmittance in the total infrared spectrum of MCAM 121 (Figure 10) is observed for specially vibration band of metal oxides and its spinels after the $\mathrm{H}_{2}$ exposure to the mixed oxides surface. Dissociative hydrogen binds weekly with the oxides surface as $\mathrm{MO}-\mathrm{H}$ (where, $\mathrm{M}=\mathrm{Mg}$ or $\mathrm{Co}$ ) which might be the cause of the reduction of transmittance. It can be considered through this analysis that the adsorbed hydrogen in the present study is physisorption dominant. 


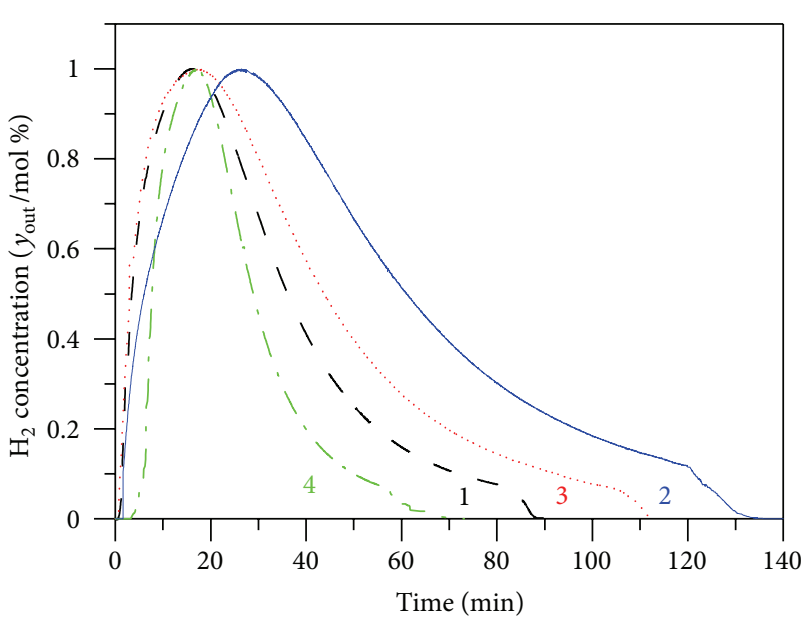

(1) MCAM031

(2) MCAM121

(3) MCAM211

(4) MCAM301

FIGURE 8: Desorption (normalized concentration in mol\%) curves of MCAM with different molar ratios.

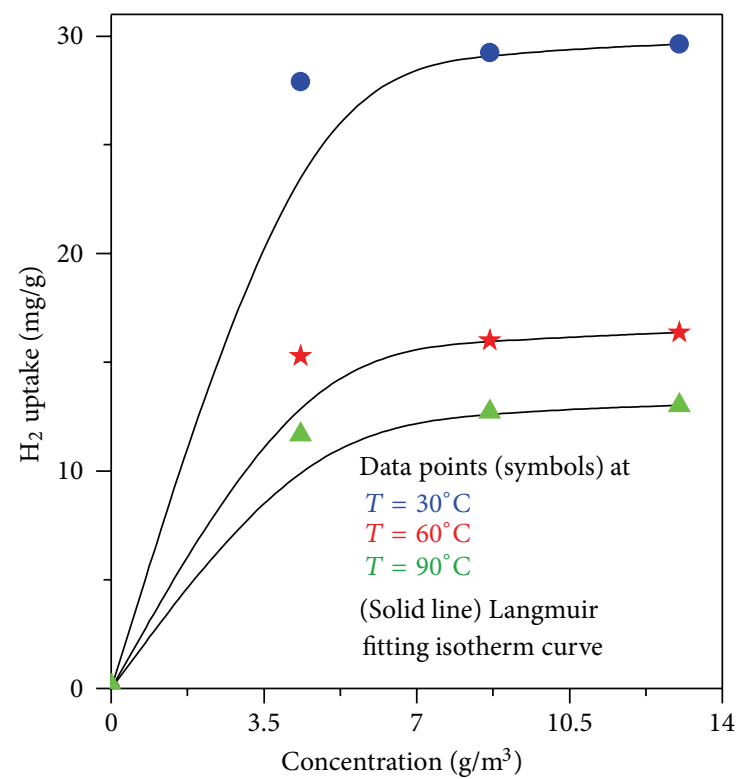

Figure 9: Adsorption isotherms of hydrogen at different temperature.

3.3. $\mathrm{H}_{2}$ Adsorption Kinetics and Thermodynamics. The hydrogen adsorption rate can be calculated by using a linear driving force model:

$$
\text { Rate }=\frac{d W}{d t}=k\left(w-w_{t}\right),
$$

where $w$ is the adsorption capacity $(\mathrm{mg} / \mathrm{g})$ and $k$ is the adsorption rate constant (per min). The initial rate of the adsorption indicates the maximum driving force $(w)$. The adsorption rate constant can be determined by using the following expression:

$$
k=\frac{\text { initial rate of adsorption }}{\text { adsorption capacity }} .
$$

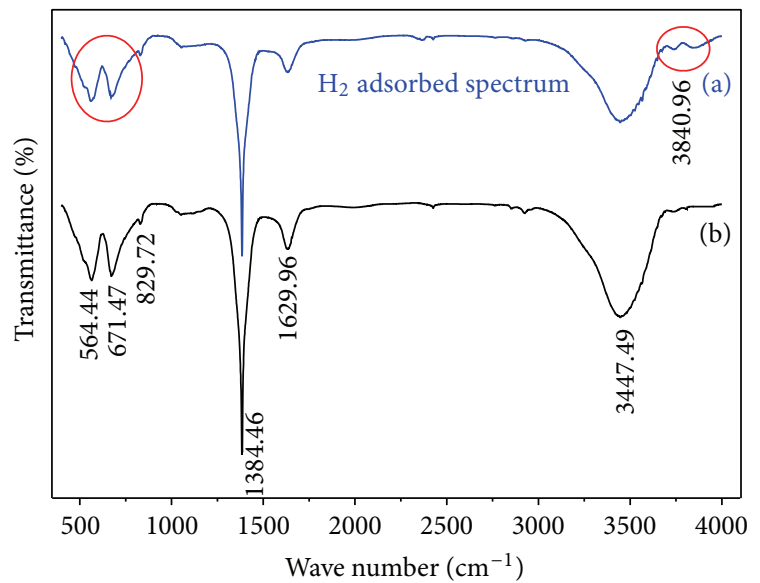

FIgURE 10: FTIR spectra of (a) hydrogen adsorbed MCAM 121 (blue solid line) and (b) MCAM 121.

The adsorption rate constant depends on the temperature that can be estimated by the Arrhenius equation [35]:

$$
\ln k=\ln k_{0}-\frac{E_{a}}{R T}
$$

where $E_{a}$ is the activation energy and $k_{0}$ is the preexponential factor. $R$ and $T$ are the universal gas constant and the temperature in $\mathrm{K}$, respectively. The calculated activation energy and preexponential factor from the linear plot of $\ln k$ versus $1 / T$ (Figure 11) are $4.22 \mathrm{~kJ} / \mathrm{mol}$ and $27.24 \mathrm{~S}^{-1}$. The lower activation energy of the MCAM 121 indicated that the phenomenon is a physical adsorption and exothermic [28]. The desorbed amount of $\mathrm{H}_{2}$ (Table 2) and the small activation energy indicated that the adsorption is physisorption dominant and that less activation might be needed to adsorb hydrogen with intermediate adsorption.

The Vant Hoff equation is an important tool to study the $\mathrm{H}_{2}$ adsorption thermodynamics and can be defined in the form $[29,30]$

$$
\Delta G_{\mathrm{ads}}=-R T \ln K_{L}=\Delta H_{\mathrm{ads}}-T \Delta S_{\mathrm{ads}},
$$

where $K_{L}$ is the standard equilibrium constant of the Langmuir type adsorption $R$ is the universal gas constant. $\ln K_{L}$ versus $1 / T$ plot (Figure 11) shows the linear relationship between them. The change of entropy $\left(\Delta S_{\text {ads }}\right)$ and enthalpy $\left(\Delta H_{\mathrm{ads}}\right)$ of the hydrogen adsorption on the mixed oxides (MCAM 121) can be determined from the plot (Figure 12). The values of $\Delta H_{\mathrm{ads}}, \Delta S_{\mathrm{ads}}$ are calculated as $-25.58 \mathrm{~kJ} / \mathrm{mol}$, $-59.98 \mathrm{~J} / \mathrm{mol} \cdot \mathrm{K}$ which showed that the adsorption process is exothermic and unfavorable for high temperatures. The negative value of the entropy indicated that the randomness of the hydrogen decreased from the molecular state to the adsorbed state and the regular ordering of the hydrogen on the mixed oxides surface. The value of the $\mathrm{H}_{2}$ adsorption enthalpy change pointed out that the interactions are in the physisorption range $(20-40 \mathrm{~kJ} / \mathrm{mol})$. hydrogen physisorption 
TABLE 4: Comparison of thermodynamics and kinetics data.

\begin{tabular}{lcccc}
\hline Adsorbent & $-\Delta H /(\mathrm{kJ} / \mathrm{mol})$ & $-\Delta S /(\mathrm{J} / \mathrm{mol} \cdot \mathrm{K})$ & $E_{a} /(\mathrm{kJ} / \mathrm{mol})$ & References \\
\hline MCAM 121 & 25.58 & 59.98 & 4.22 & - \\
Mg-MOF-74 & 9.40 & 120 & - & This work \\
Co-MOF-74 & 11.20 & 130 & - & {$[1]$} \\
(Mg, Na)-Y & 18.00 & 136 & - & {$[1]$} \\
Na-ZSM-5 & 10.30 & 121 & {$[28]$} \\
Pd-InP & 44.10 & 125.5 & 20.20 & {$[29]$} \\
Pd-GaAs & 33.50 & - & {$[30]$} \\
\hline
\end{tabular}

$\Delta H$ Change of ads. enthalpy, $\Delta S$ Change of ads. Entropy; $E_{a}$ Activation energy.

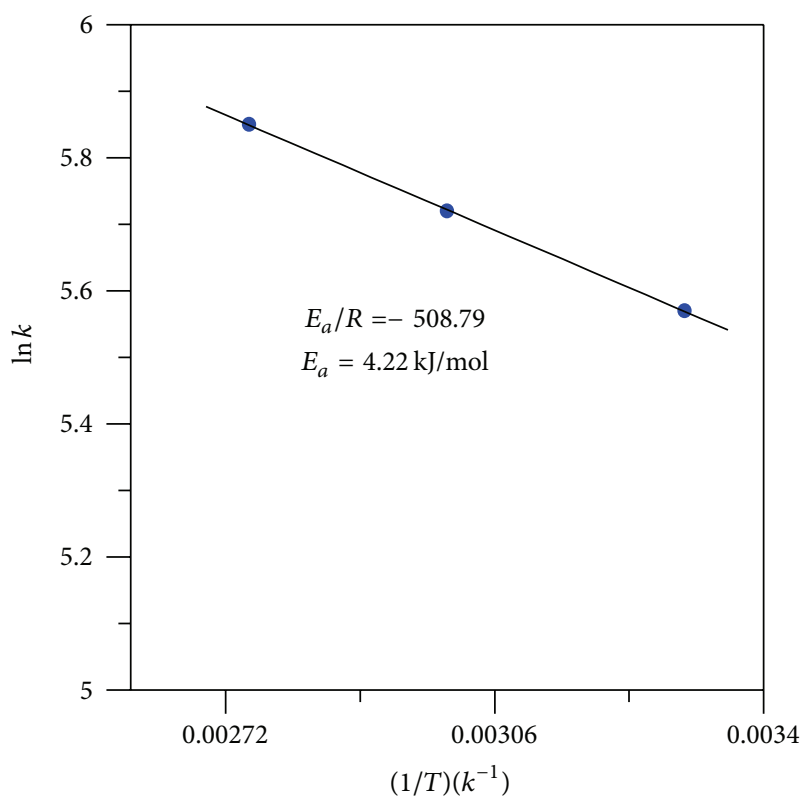

FIGURE 11: The dependence of logarithmic value of adsorption rate constant on inverse temperature (MCAM 121).

thermodynamics can be optimized for porous adsorbents by using the Bhatia and Myers derived equation [31]:

$$
H_{\mathrm{opt}}=T \Delta S_{\mathrm{ads}}+\left[\left(\frac{R T}{2}\right) \ln \left(\frac{P_{1} P_{2}}{P_{0}^{2}}\right)\right] .
$$

Equation (9) can be used to predict optimum adsorption enthalpy value. According to (9), where the value is near or equal to $19.05 \mathrm{~kJ} / \mathrm{mol}$, the potential adsorption enthalpy for hydrogen adsorption might be considered on mixed oxides at an ambient temperature and pressure where the entropy change must be an important factor. A comparison has been made on the kinetics and thermodynamics of hydrogen storage materials $[9,36-40]$ and is shown in Table 4 . The change of enthalpy and entropy and the activation energy of the mixed oxides that come from this investigation are very promising for reversible hydrogen storage adsorbents. Desorption capacity indicates that adsorbed hydrogen did not desorb fully because of partial chemical adsorption. Regeneration of adsorbent indicates that the hydrogen adsorption

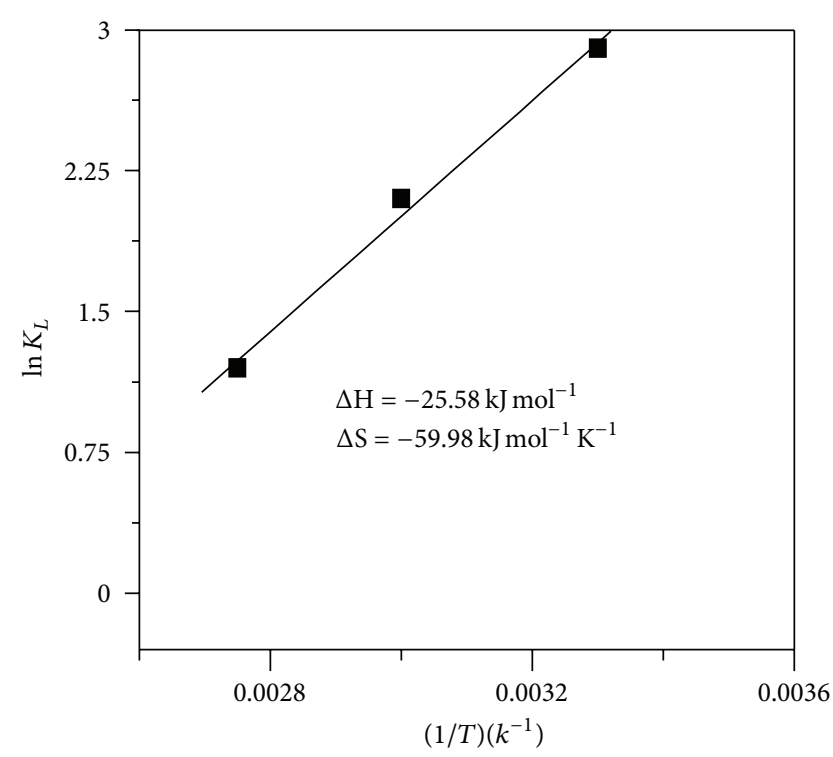

FIGURE 12: The dependence of logarithmic value of equilibrium constant on inverse temperature (MCAM 121).

capacity of mixed oxide is not the same for all cycle but capacities are in range of $22-28 \mathrm{mg} / \mathrm{g}$ adsorbent. In conclusion, Adsorption through physical and chemical ways might be the right way to achieve the target. It is a future interest of us to analyze reduced mixed oxide at ambient condition for hydrogen adsorption and to study its thermodynamics and kinetics.

\section{Conclusions}

Porous and homogenous nanocrystalline mixed oxides as adsorbents have been synthesized for fixed bed. The $\mathrm{H}_{2}$ adsorption breakthrough curves have been carried out for different temperatures and concentrations to investigate the adsorption performance of the mixed oxides. The FTIR technique has been used to observe the hydrogen spillover in $\mathrm{H}_{2}$ adsorbed mixed oxides. The outcome of the investigation implies that adsorption capacity increases with the surface area and with a higher cobalt loading, coral-like porous surface, and favorable electric field produced by different oxides in spinels. The Langmuir isotherm model depicted 
a $3 \mathrm{wt} \%$ hydrogen adsorption whereas it showed desorption $43 \%-57 \%$ of the adsorbed $\mathrm{H}_{2}$. It can be concluded that the developed materials showed promising quantitative data of the kinetics and thermodynamics of $\mathrm{H}_{2}$ adsorption on unreduced mixed oxides. The material can be considered for different industrial uses as energy carrier.

\section{Acknowledgments}

The authors would like to thank ministry of higher education of Malaysia (MOHE) for the FRGS Grant 158-200-092, lab facilities of UTP and would like to thank Dixon SDN BHD,Malaysia, for their cooperation in fabricating the fixed bed adsorption column.

\section{References}

[1] C. P. Baldé, Hereijgers, B. P. C. Bitter, and K. P. Jong, "Facilitated hydrogen storage in $\mathrm{NaAlH}_{4}$ supported on carbon nanofibers," Angewandte Chemie - International Edition, vol. 45, no. 21, pp. 3501-3503, 2006.

[2] A. Gutowska, L. Li, Y. Shin et al., "Nanoscaffold mediates hydrogen release and the reactivity of ammonia borane," Angewandte Chemie-International Edition, vol. 44, no. 23, pp. 3578-3582, 2005.

[3] G. L. Bezemer, J. H. Bitter, H. P. C. E Kuipers et al., "Cobalt particle size effects in the Fischer-Tropsch reaction studied with carbon nanofiber supported catalysts," Journal of the American Chemical Society, vol. 128, no. 12, pp. 3956-3964, 2006.

[4] A. T. Bell, "The impact of nanoscience on heterogeneous catalysis," Science, vol. 299, no. 5613, pp. 1688-1691, 2003.

[5] F. Schüth, B. Bogdanovic, and M. Felderhof, "Light metal hydrides and complex hydrides for hydrogen storage," Chemical Communications, vol. 37, no. 20, pp. 2249-2258, 2004.

[6] W. Grochala and P. P. Edwards, "Thermal decomposition of the non-interstitial hydrides for the storage and production of hydrogen," Chemical Reviews, vol. 104, no. 3, pp. 1283-1315, 2004.

[7] S. I. Orimo, Y. Nakamori, J. R. Eliseo, A. Züttel, and C. M. Jensen, "Complex hydrides for hydrogen storage," Chemical Reviews, vol. 107, no. 10, pp. 4111-4132, 2007.

[8] B. Bogdanovic, U. Eberle, M. Felderhoff, and F. Schüth, "Complex aluminum hydrides," Scripta Materialia, vol. 56, no. 10, pp. 813-816, 2007.

[9] C. O. Areán, S. Chavan, C. P. Cabello, E. Garrone, and G. T. Palomino, "Thermodynamics of hydrogen adsorption on metal-organic frameworks," ChemPhysChem, vol. 11, no. 15, pp. 3237-3242, 2010.

[10] K. M. Thomas, "Hydrogen adsorption and storage on porous materials," Catalysis Today, vol. 120, no. 3-4, pp. 389-398, 2007.

[11] M. A. . Salam, Y. Lwin, and S. Suriati, "Synthesis of nanostructured Ni-Co-Al hydrotalcites and derived mixed oxides," Advanced Materials Research, vol. 626, pp. 173-177, 2013.

[12] M. A. Salam, S. Sufian, and Y. Lwin, "Hydrogen adsorption study on mixed oxides using the density functional theory," Journal of Physics and Chemistry of Solids, vol. 74, no. 4, pp. 558564, 2013.

[13] Q. Sun, P. Jena, Q. Wang, and M. Marquez, "First-principles study of hydrogen storage on $\mathrm{Li}_{12} \mathrm{C}_{60}$," Journal of the American Chemical Society, vol. 128, no. 30, pp. 9741-9745, 2006.
[14] S. H. Jhi, Y. K. Kwon, K. Bradley, and J. C. P. Gabriel, "Hydrogen storage by physisorption: beyond carbon," Solid State Communications, vol. 129, no. 12, pp. 769-773, 2004.

[15] J. Z. Larese, T. Arnold, L. Frazier, R. J. Hinde, and A. J. RamirezCuesta, "Direct observation of $\mathrm{H}_{2}$ binding to a metal oxide surface," Physical Review Letters, vol. 101, no. 16, Article ID 165302, 4 pages, 2008.

[16] Z. Yong, V. Mata, and A. E. Rodrigues, "Adsorption of carbon dioxide onto hydrotalcite-like compounds (HTlcs) at high temperatures," Industrial and Engineering Chemistry Research, vol. 40, no. 1, pp. 204-209, 2001.

[17] L. Zhao, X. Li, X. Quan, and G. Chen, "Effects of surface features on sulfur dioxide adsorption on calcined nial hydrotalcite-like compounds," Environmental Science and Technology, vol. 45, no. 12, pp. 5373-5379, 2011.

[18] J. Yu, Z. Jiang, L. Zhu, Z. P. Hao, and Z. P. Xu, "Adsorption/ desorption studies of NOx on well-mixed oxides derived from Co-Mg/Al hydrotalcite-like compounds," Journal of Physical Chemistry B, vol. 110, no. 9, pp. 4291-4300, 2006.

[19] S. Cavenati, C. A. Grande, and A. E. Rodrigues, "Adsorption Equilibrium of methane, carbon dioxide, and nitrogen on zeolite $13 \mathrm{X}$ at high pressures," Journal of Chemical and Engineering Data, vol. 49, no. 4, pp. 1095-1101, 2004.

[20] S. Sircar and J. W. Zondlo, "Fractionation of air by adsorption," US patent 4 007.779, 1978.

[21] T. L. P. Dantas, F. M. T. Luna, J. I. J. Silva et al., "Modeling of the fixed-bed adsorption of carbon dioxide and a carbon dioxidenitrogen mixture on zeolite 13X," Brazilian Journal of Chemical Engineering, vol. 28, no. 3, pp. 533-544, 2011.

[22] R. L. Frost and S. J. Palmer, "The effect of synthesis temperature on the formation of hydrotalcites in Bayer liquor: a vibrational spectroscopic analysis," Applied Spectroscopy, vol. 63, no. 7, pp. 748-752, 2009.

[23] C. C. Rodrigues, M. J. Deovaldo, S. W. Nobrega, and M. G. Barboza, "Ammonia adsorption in a fixed bed of activated carbon," Bioresource Technology, vol. 98, no. 4, pp. 886-891, 2007.

[24] K. Tanaka, Y. Kanda, M. Furuhashi, K. Saito, K. Kuroda, and H. Saka, "Improvement of hydrogen storage properties of meltspun Mg-Ni-RE alloys by nanocrystallization," Journal of Alloys and Compounds, vol. 293, pp. 521-525, 1999.

[25] J. A. Delgado, M. A. Uguina, J. L. Sotelo, B. Ruíz, and J. M. Gómez, "Fixed-bed adsorption of carbon dioxide/methane mixtures on silicalite pellets," Adsorption, vol. 12, no. 1, pp. 5$18,2006$.

[26] J. T. Kloprogge and R. L. Frost, "Fourier transform infrared and raman spectroscopic study of the local structure of $\mathrm{Mg}$-, $\mathrm{Ni}$-, and Co-hydrotalcites," Journal of Solid State Chemistry, vol. 146, no. 2, pp. 506-515, 1999.

[27] M. G. Nijkamp, J. E. M. J Raaymakers, A. J. Dillen, and K. P. Jong, "Hydrogen storage using physisorption-materials demands," Applied Physics A, vol. 72, no. 5, pp. 619-623, 2001.

[28] D. Saha, Z. Wei, and S. Deng, "Equilibrium, kinetics and enthalpy of hydrogen adsorption in MOF-177," International Journal of Hydrogen Energy, vol. 33, no. 24, pp. 7479-7488, 2008.

[29] Y. Lwin and F. Abdullah, "High temperature adsorption of carbon dioxide on $\mathrm{Cu}-\mathrm{Al}$ hydrotalcite-derived mixed oxides: kinetics and equilibria by thermogravimetry," Journal of Thermal Analysis and Calorimetry, vol. 97, no. 3, pp. 885-889, 2009.

[30] S. Lifang, W. Shuang, J. Chengli et al., "Thermodynamics study of hydrogen storage materials," Journal of Chemical Thermodynamics, vol. 46, pp. 86-93, 2012.

[31] S. K. Bhatia and A. L. Myers, "Optimum conditions for adsorptive storage," Langmuir, vol. 22, no. 4, pp. 1688-1700, 2006. 
[32] E. V. Benvenutti, L. Franken, C. C. Moro, and C. U. Davanzo, "FTIR study of hydrogen and carbon monoxide adsorption on $\mathrm{Pt} / \mathrm{TiO}_{2}, \mathrm{Pt} / \mathrm{ZrO}_{2}$, and $\mathrm{Pt} / \mathrm{Al}_{2} \mathrm{O}_{3}$," Langmuir, vol. 15, no. 23, pp. 8140-8146, 1999.

[33] E. Guglielminotti, F. Boccuzzi, G. Ghiotti, and A. Chiorino, "Infrared evidence of metal-semiconductor interaction in a Ru/ZnO system," Surface Science, vol. 189-190, pp. 331-338, 1987.

[34] M. Haneda, T. Watanabe, and M. Ozawa, "Characterization and reactivity analysis of hydrogen adspecies on platinum nanoparticles supported on alumina," Journal of the Japan Petroleum Institute, vol. 55, no. 3, pp. 191-196, 2012.

[35] R. J. Sibley and R. A. Alberty, Physical Chemistry, John Wiley \& Sons, New York, NY, USA, 3rd edition, 2001.

[36] M. Delavar, M. A. Ghoreyshi, M. Jahanshahi, S. khalili, and N. Nabian, "Equilibria and kinetics of natural gas adsorption on multi-walled carbon nanotube material," RCS Advances, vol. 2, no. 10, pp. 4490-4497, 2012.

[37] G. T. Palomino, M. R. L. Carayol, and C. O. Areán, "Hydrogen adsorption on magnesium-exchanged zeolites," Journal of Materials Chemistry, vol. 16, no. 28, pp. 2884-2885, 2006.

[38] C. O. Areán, O. V. Manoilova, B. Bonelli, M. R. Delgado, G. T. Palomino, and E. Garrone, "Thermodynamics of hydrogen adsorption on the zeolite Li-ZSM-5," Chemical Physics Letters, vol. 370, no. 5-6, pp. 631-635, 2003.

[39] H. I. Chen, Y. I. Chou, and C. K. Hsing, "Comprehensive study of adsorption kinetics for hydrogen sensing with an electrolessplated Pd-InP Schottky diode," Sensors and Actuators B, vol. 92, no. 1-2, pp. 6-16, 2003.

[40] W. P. Kang and Y. Gurbuz, "Comparison and analysis of Pdand Pt-GaAs Schottky diodes for hydrogen detection," Journal of Applied Physics, vol. 75, no. 12, pp. 8175-8181, 1994. 

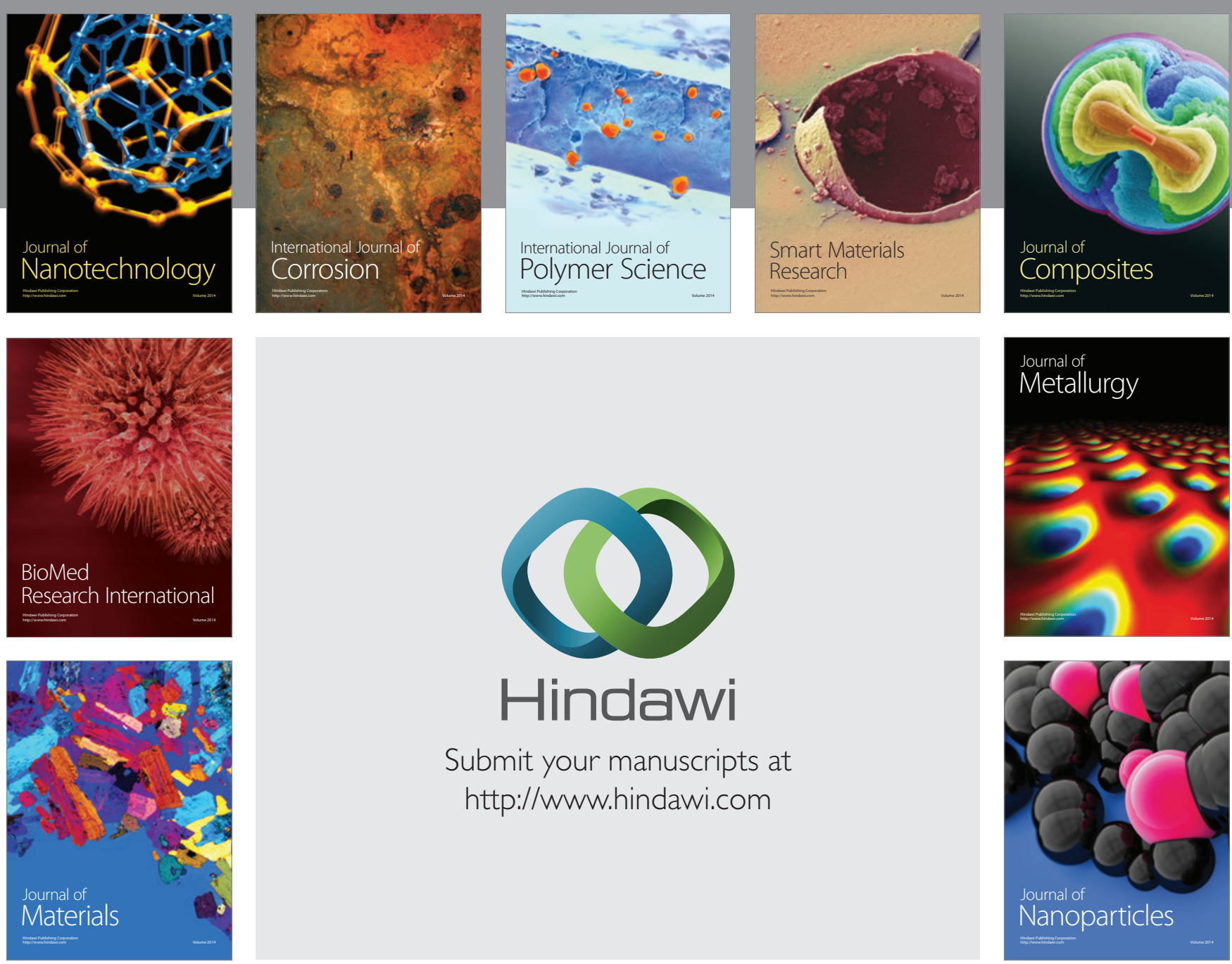

Submit your manuscripts at http://www.hindawi.com
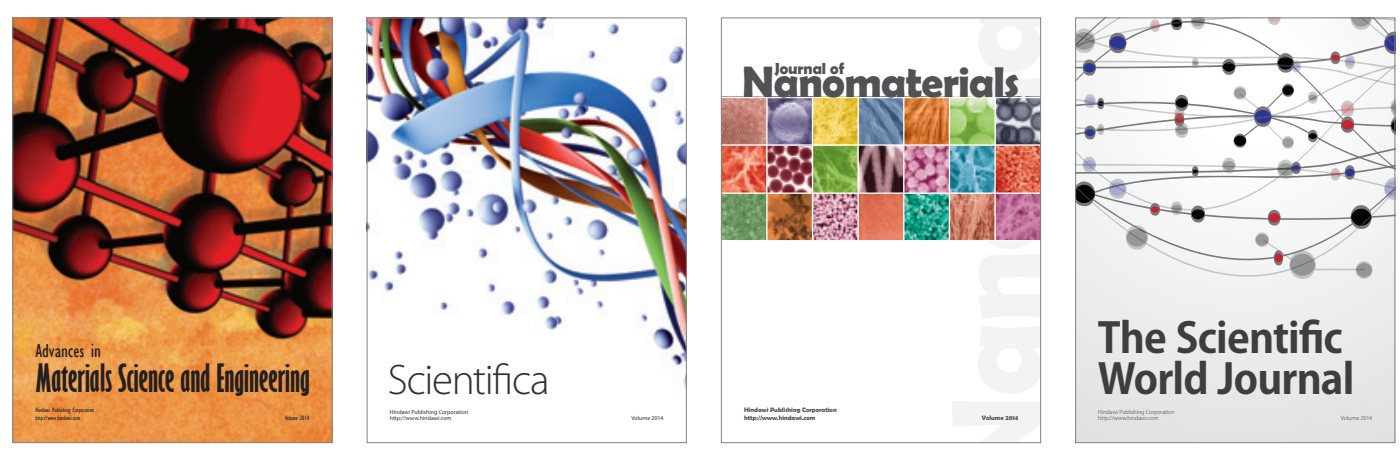

\section{The Scientific World Journal}
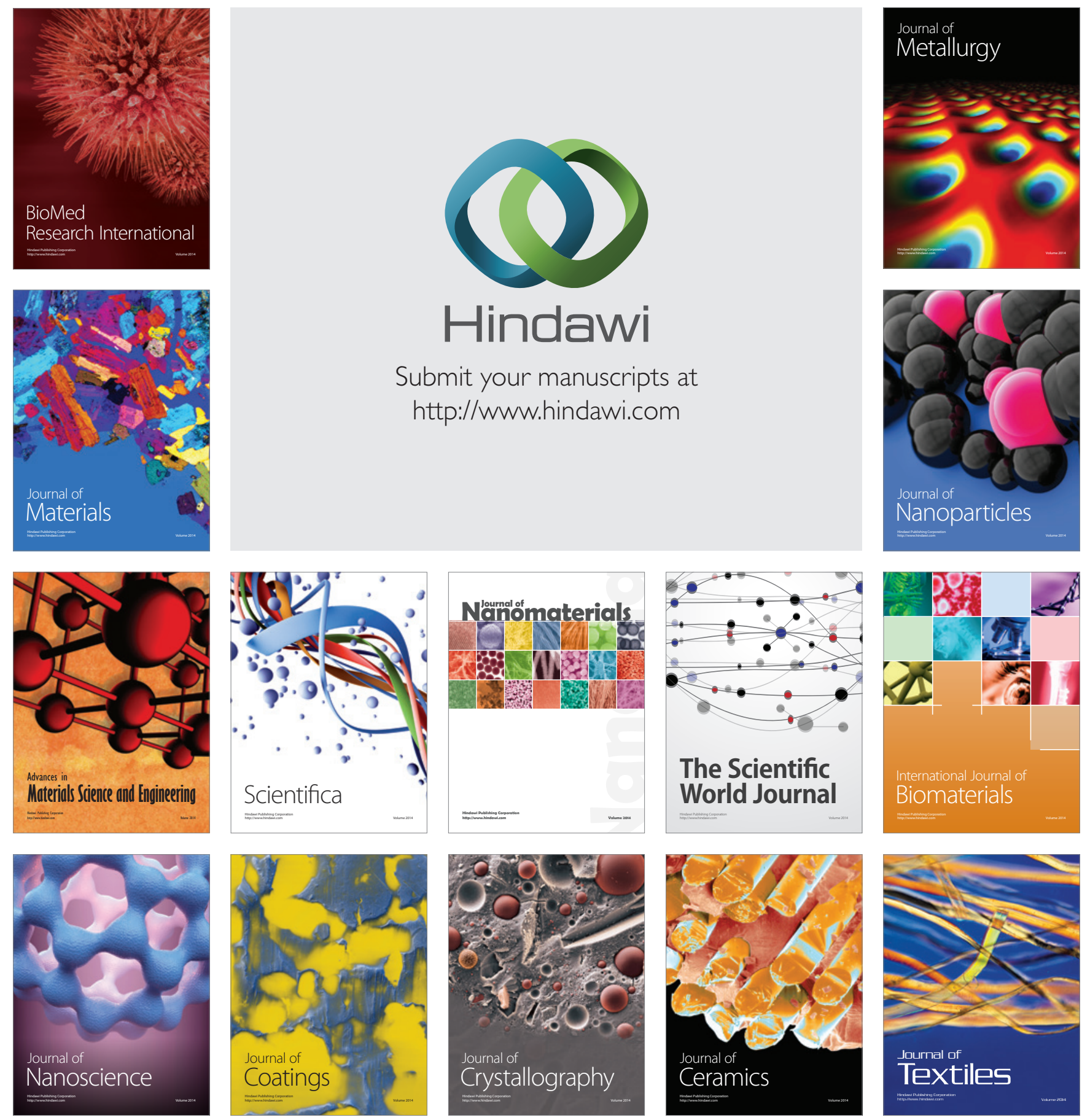